\title{
THE LOCAL NATURE OF MODERN MORAL SKEPTICISM
}

BY

\author{
DIEGO E. MACHUCA
}

\begin{abstract}
Julia Annas has affirmed that the kind of modern moral skepticism which denies the existence of objective moral values rests upon a contrast between morality and some other system of beliefs about the world which is not called into doubt. Richard Bett, on the other hand, has argued that the existence of such a contrast is not a necessary condition for espousing that kind of moral skepticism. My purpose in this paper is to show that Bett fails to make a good case against Annas' thesis. To accomplish this, it will be helpful to consider the Pyrrhonean attitude towards morality as expounded in Sextus Empiricus' work.
\end{abstract}

\section{Introduction}

One of the most common forms of modern moral skepticism denies that moral values or moral facts are part of the objective world. The leading proponent of this view is John Leslie Mackie, who in his influential book Ethics defines his moral skepticism as the "negative doctrine [which] says that there do not exist entities or relations of a certain kind, objective values or requirements, which many people have believed to exist" (1977, p. 17). ${ }^{1}$ This kind of skeptical position is usually designated 'ontological moral skepticism', in opposition to epistemological versions of moral skepticism, such as the view which denies that moral knowledge is possible, or that which denies that moral beliefs are justified. ${ }^{2}$ In the 1980 s, a discussion took place between Julia Annas and Richard Bett over whether ontological moral skepticism depends upon a contrast between morality and some other system of beliefs about the world which is not called into question. The discussion was couched in terms of whether ontological moral skepticism is "local", since if this skepticism rests upon such a

Pacific Philosophical Quarterly 87 (2006) 315-324

(C) 2006 The Author

Journal compilation (C) 2006 University of Southern California and Blackwell Publishing Ltd. 
contrast, then it is not a part of a global skepticism that questions the truth of all beliefs. Annas claimed that ontological moral skepticism is by nature local, which gave rise to Bett's objection. ${ }^{3}$ Unfortunately, there has been no subsequent analysis of the cogency of Bett's argument against Annas' position, and hence no further examination of whether or not the latter's thesis is correct. I believe that such an analysis is still relevant, because it will allow us to identify more clearly the theoretical underpinnings of the view that morality is not objective - a view that is quite common nowadays. The aim of the present paper is therefore to continue the discussion between Annas and Bett about the local character of ontological moral skepticism. Since it is Annas' and Bett's usage, I will employ the label 'modern moral skepticism' to refer specifically to ontological moral skepticism.

I will begin by presenting Annas' view about the local character of modern moral skepticism. Then I will expound Bett's argument against it. Next, I will portray in broad outline the skeptical outlook regarding morality that is found in the works of the 2nd century Greek Pyrrhonist Sextus Empiricus, since this will make it possible to discern more clearly whether being local is essential to modern moral skepticism. Finally, I will argue that Bett does not succeed in proving Annas' thesis false. ${ }^{4}$

\section{Annas' position}

Annas contends that the view which denies the existence of objective moral values is based on the idea that moral realism conflicts with our knowledge of the world. That is to say, the underlying idea is that the ethical theories that assert the existence of such values conflict with a view of the world which is objective and shared by all, and which affirms the existence of other kinds of entities. ${ }^{5}$ Within this frame, Annas refers to two common lines of argumentation advanced by modern moral skepticism. According to the first, "moral values are not real because there is so much dispute about them and no clear way of resolving it" (1998, p. 205). Also, in moral inquiry, in contrast to other fields of inquiry, there seem to be no acknowledged experts, no progress, and no accumulation of knowledge. Annas points out that the empirical sciences are the model with which morality is usually contrasted, given that the "norms of objectivity which morality is deemed to fail are bound to be found, if at all, in the natural sciences" (1998, p. 205). Therefore, the contrast with morality would disappear and moral skepticism would lose its basis, were scientific knowledge to become a target of skeptical attack.

The other line of argumentation put forward by modern moral skepticism does not focus on the shortcomings of moral inquiry. Rather, it advances a particular conception of its subject matter: moral values do not exist 
independently of us, but are merely our projections. That is to say, moral values are not objective:

if the world as it really is, is like that: as it would be described from the non-human, absolute viewpoint. Here the moral scepticism rests crucially on the confidence that there is such a viewpoint, even if it is one that we have not attained and never shall. (And, again, it would be useless to deny that a part is played in this by the belief that this is what science actually or ideally aims at). (1998, p. 206)

Hence, if the point of view which objectively describes the world were undermined, the contrast with morality would vanish and moral skepticism would lose its foundation.

Annas' view, then, is that modern moral skepticism is local because it is based upon a contrast between morality and some other system of beliefs whose truth is not questioned. But she is more specific and presents science as the one way of looking at the world that is immune to skeptical attack. According to her, in both sources of modern moral skepticism to which she refers, confidence in the objectivity of science plays a key role in the argumentation which leads to the denial of the existence of objective moral values. ${ }^{6}$ Annas' remarks regarding the status of science appear not merely to report the fact that modern moral skepticism predominantly adopts a non-skeptical attitude towards science, ${ }^{7}$ but to attempt to show that it is not possible to espouse this skepticism unless one believes in the descriptive and explanatory power of science. However, this appearance is misleading, since in closing her discussion of the local character of modern moral skepticism, she points out that this skepticism "is essentially local, a part of a globally unsceptical world-view which is likely to be scientifically based ..." (1998, p. 207; emphasis added). Thus, though Annas contends that confidence in the objectivity of science is the probable basis for denying the existence of objective moral values, she does not believe that it is the only possible basis. ${ }^{8}$

\section{Bett's objection}

As already indicated, Bett opposes the view that, to deny the existence of objective moral values, it is necessary that modern moral skepticism be local. In making his case against this view, Bett argues that there are two ways in which someone who is skeptical of morality and who has confidence in the possibility of objective descriptions of reality may lose this confidence. On the one hand, he may come to the conclusion that the notion of an "objective" world does not make sense, in which case it would make no sense either to affirm or to deny that there exists an adequate way of describing the world as it is in itself. By the same token, it would 
make no sense either to adopt or to reject moral skepticism, i.e. the position which maintains that moral values are not part of the world as it is independently of us. On the other hand, it is possible that he considers that the notion of an objective reality does make sense, but denies that science, or any other view of the world, can describe such a reality. According to Bett, there is no reason to believe that, in this case, one should abandon one's moral skepticism, since:

The fact that one has now begun to doubt whether any of our ways of talking about the world can hope to capture it as it is in itself seems to do nothing to undermine moral skepticism; it merely seems to show that we are as badly off in all areas as we were previously claimed to be in morality. (1988, p. 105)

Thus, one could continue to be skeptical of morality, without it being necessary to believe that science or any other view of the world accounts for what reality is like in its real nature.

\section{The Pyrrhonean stance}

In this section, I will briefly describe the moral skepticism found in Sextus Empiricus' work. The reason for offering this description is that, by contrasting the Pyrrhonist's outlook with that of the modern skeptic, it will be easier to assess in the next section whether Bett's position has any basis.

The Pyrrhonist neither affirms nor denies the existence of objective moral values, ${ }^{9}$ since in ethics, as in all other fields of inquiry, he finds conflicts between incompatible arguments which appear to him to be of equal force (isostheneia). The fact that the conflicting positions seem to have the same weight renders the conflicts unresolvable (anepikritoi). More precisely, the Pyrrhonist finds (i) an unresolvable disagreement among ethical theories which have differing views about what the good, the bad, and the indifferent are, (ii) an unresolvable disagreement about what things those notions apply to, and (iii) an unresolvable disagreement between the ethical theories which affirm and those which deny that things are good, bad, or indifferent by nature. Since it is impossible to assent to any of the seemingly equipollent positions in these disagreements, the Pyrrhonist suspends judgment (Pyrrōneioi Hypotypōseis [PH] III 178, 182, 235; Adversus Dogmaticos $[A D] \mathrm{V} 111,144)$. Hence, the mere fact that there is diversity of points of view, opinions, or theories is not in itself sufficient to induce suspension of judgment (epoche)): it is also necessary that none of them appear to have more weight than the others. ${ }^{10}$

The Pyrrhonist does not assert that each of the issues about which he suspends judgment is in itself unresolvable; ${ }^{11}$ rather, he continues to investigate the questions for which he has not as yet found any answer 
(e.g. PH I 1-3, II 11). Nor does he affirm that things are as he says they are; he makes it clear that when he employs the term 'is' (esti), for instance, it must be understood not in the sense of 'really is', but in the sense of 'appears' (phainetai) (PH I 135, 198, AD V 18-20). Thus, if he says ' $I$ think murder is bad', what he means is 'Murder appears bad to me'. The Pyrrhonist, then, restricts his discourse to the realm of his own appearances (e.g. $P H$ I 17, 19-22), and suspends judgment as to what the real nature of things is (e.g. $P H$ I 78, 128, 134, 140, 163, 167). According to him, it is the "dogmatist" who gives his assent to positive or negative assertions about the nature of reality. ${ }^{12}$

To get an idea of the Pyrrhonean attitude at work, it may be helpful to imagine how a Pyrrhonist would deal with a given disagreement - say, the disagreement about whether abortion is morally wrong. He would examine the arguments for and against abortion, trying to determine whether one of the contending views has grasped its real nature. One of the parties to the dispute will argue, for instance, that the fetus has a soul, which makes him/her a human being, and that the murder of a human being is something morally wrong. This party may also put forward an argument based upon religious beliefs: since God created the fetus, only God can make decisions about his/her death. The contrary party will probably argue that it is absurd to claim that a two-month-old fetus is a person; that the notion of a creating god does not make sense; and that we must privilege the woman's right to decide what to do with her body and life. The Pyrrhonist will weigh up these opposing arguments, and will first note that the different opinions about abortion that the two parties hold appear to be relative to factors similar to those mentioned in the so-called Tenth Mode of Aenesidemus (PH I 145-163). He will point out that such opinions seem to be dependent upon each party's familial, cultural, and social background, as well as upon its religious, metaphysical, and scientific beliefs and theories, so that one may say how abortion appears to be in relation to each of these factors, but not how it is in itself. But the Pyrrhonist's inquiry will not stop there: he will attempt to determine whether any of the contending parties can justify its claims. To do so, the Pyrrhonist will turn to three of the so-called Five Modes of Agrippa (PH I 164177), according to which, in trying to justify any claim, one falls into either infinite regress or circular reasoning, or makes an unjustified assertion. That is to say, in attempting to prove the truth of an assertion, one of the parties will have to prove the truth of the premise from which they infer the assertion, and so on ad infinitum. Or, to avoid being thrown back ad infinitum, they will try to establish the truth of one of the links of the chain of reasons by having recourse to the first link whose truth they set out to establish, thus falling into circularity. Or they will argue that one of the links of the chain needs no proof to establish its truth because it is self-evident or self-justifying. To this the Pyrrhonist will respond that the 
opposite party can proceed in exactly the same way, and hence that there is no reason to prefer one party to the other. As a result, the Pyrrhonist will be unable to resolve the dispute over the moral nature of abortion, and will therefore suspend judgment. ${ }^{13}$

In sum, the Pyrrhonean skeptic's stance is characterized by an extreme caution, which prevents him from making rash judgments about the nature and existence of anything.

\section{In response to Bett}

From the Pyrrhonean stance described in the previous section, modern moral skepticism cannot be deemed an authentic form of skepticism. Rather, it is a "dogmatic" position, since it asserts that the nature of reality is such that moral judgments are not adequate to describe and explain it. More precisely, modern moral skepticism is at the same time both a negative and a positive dogmatism. It is "negative" insofar as the modern moral skeptic denies the existence of objective moral values. It is "positive" both in an ontological and epistemological sense, since he believes that there exists an external world whose real nature he is able to know. ${ }^{14}$ It is on the basis of this knowledge that he denies that the positions which affirm the existence of objective moral values have any foundation. That is to say, negative dogmatism in ethics is the consequence of a positive dogmatism which, leaving aside the different forms that it can take, claims to know what the kinds of things that really exist are. This can be seen more clearly if we compare the ancient and modern skeptics' attitudes. The Pyrrhonist neither espouses nor rejects moral realism because he does not have access to the real nature of a supposedly existing world, and hence no way of determining whether there are any moral values. If he had confidence, for instance, in the worldview provided by physics or common sense, and if it were at odds with moral realism, then he would certainly deny the objectivity of morality. However, the Pyrrhonist does not have this kind of confidence: he is agnostic not only about moral beliefs but about all beliefs. ${ }^{15} \mathrm{He}$ would say that the arguments against morality put forward on the basis of the worldview provided by physics or common sense appear to him to be equal in force to those advanced by the moral realist, and hence that he must suspend judgment about the existence of objective moral values. On the contrary, the modern moral skeptic does believe that the arguments put forward against the existence of objective moral values are stronger than those which purport to prove their existence. That is to say, he does not suspend judgment because he thinks there are sufficient grounds for denying the objectivity of morality. This attitude can only be explained by the fact that he believes he knows what does exist and does not exist in the objective world. 
One might argue that the unresolved disagreements that exist among the defenders of moral realism show that moral values are not real. However, the fact that a disagreement is unresolved does not imply that none of the conflicting views is correct. Even if the disagreements among moral realists were in themselves unresolvable, this would not be sufficient reason for denying that moral values are objective, for the existence of an unresolvable disagreement only manifests the impossibility of determining which of the positions in conflict, if any, is correct. Hence, to deny the objectivity of morality, one needs more than unresolved or unresolvable conflicts of moral positions: one needs an objective view of the world with which moral realism is at odds.

If the allegedly non-local moral skeptic portrayed by Bett does not have confidence in the objectivity of any view of the world, one should ask how he can know that all our representations of reality fail to describe and explain it. Indeed, it would seem that, to know that there is no correspondence whatsoever between any of our ideas and the objective world, Bett's non-local moral skeptic must paradoxically have some kind of cognitive access to the true nature of this very thing our ideas fail to represent adequately, so as to be able to test them. Furthermore, if according to the allegedly non-local moral skeptic described by Bett our ideas do not adequately represent anything outside us, one should ask how he can know that there exists a mind-independent world in the first place, since concepts such as "mind-independent existence" and "objective world" are also ideas of ours which might correspond to nothing. Hence, to be sure that there exists a mind-independent world, one must have confidence in the objective validity of at least some of one's concepts.

From what has been said, it is clear that I cannot accept the following reasoning by Bett in its totality:

If it turns out that the status of science is no different from that of morality, that does not show that morality is not in bad shape after all; if anything, it simply shows that science is in bad shape as well. Again, the moral sceptic will need to be able to explain clearly what it is that morality is lacking; but it is not clear why this would require pointing to something else that is not lacking in the relevant respects. (1988, p. 106)

I cannot accept the second part of this argument. Although the affirmation that science does not describe the world as it is in itself does not entail the abandonment of moral skepticism, the claim that both morality and science are not objective necessarily presupposes the possession of some view of the world which is deemed to be objective. For to affirm that moral and scientific entities do not exist in the objective world, it is indeed necessary to possess some kind of knowledge about what entities do form part of that world.

By now it should be plain that the allegedly non-local moral skeptic portrayed by Bett cannot consistently affirm that none of our ways of 
talking about the world succeeds in describing it in an objective way. In my view, Bett's claim that modern moral skepticism is not essentially local seems to be based upon an invalid inference. For from the fact that, to deny the objectivity of morality, it is not necessary to be confident in the truth of every other system of beliefs, Bett invalidly infers that, to deny the objectivity of morality, one need not be certain about the objectivity of any other system of beliefs.

To sum up: one can deny the existence of objective moral values without having to be skeptical only about morality or non-skeptical about science; but this denial necessarily presupposes confidence in the objectivity of some view of the world with which moral realism is at odds. Hence, Annas is right when she maintains that modern moral skepticism is essentially local. ${ }^{16}$

\section{Consejo Nacional de Investigaciones Científicas y Técnicas Argentina}

\section{NOTES}

${ }^{1}$ Several authors have adopted Mackie's kind of moral skepticism. Among them are Snare, 1984; Black, 1989-1990, and Garner, 1990 (though the latter prefers to designate his position "anti-moral realism").

${ }^{2}$ Of course, epistemological moral skepticism is implied by ontological moral skepticism (but not vice versa). For, if there are no objective moral values or facts, all moral judgments are false (Mackie's "error theory": 1977, pp. 35, 48-49), and therefore there can be no moral knowledge and no justification for moral beliefs.

${ }^{3}$ The idea that ontological moral skepticism is local was first advanced in Annas and Barnes, 1985, p. 165, but was fully developed in an essay by Annas published in Schofield and Striker, 1986, pp. 3-29. This essay, which is the one discussed in Bett, 1988, was reprinted in 1998 (see Annas, 1998). I will use this latter version.

${ }^{4}$ I will only refer to the sense of the adjective 'local' dealt with in Annas, 1998 and Bett, 1988, leaving aside the sense according to which modern skeptical arguments against morality do not extend the scope of their conclusions to all the areas of our life. Annas introduces this second sense in Annas, 1996, pp. 210-211.

${ }^{5}$ Mackie defines the metaphysical part of what he calls "the argument from queerness" in this way: "If there were objective values, then they would be entities or qualities or relations of a very strange sort, utterly different from anything else in the universe" (1977, p. 38).

${ }^{6}$ Francis Snare explicitly presents the moral skepticism he defends as depending on a contrast between morality and science. He affirms that "we have reason to suppose there is a better account, one which fits in better with existing sciences, than the one in terms of the existence of autonomous moral facts", and that the moral skeptic "takes a non-sceptical stand in his philosophy of science" (1984, p. 223). Even though Snare recognizes that within the conceptual framework which the moral skeptic considers to account objectively for the nature of the world "there is also quite a bit of 'everyday' description and explanation which belongs to no formal science", he maintains that everyday concepts and beliefs are accepted only if they do not come into conflict with the "well-founded formal sciences" (p. 218). 
${ }^{7}$ Lowell Kleiman, too, has seen that the moral skepticism espoused by, among others, Mackie and Gilbert Harman depends upon a contrast between morality and science. According to him, these skeptics "suggest that because of science, especially the social sciences, morality does not provide the best explanation of human conduct or belief" $(1989$, p. 161). That is to say, morality is rejected because moral explanation conflicts with scientific explanation, which is the best available.

${ }^{8}$ Annas also makes this clear in Annas, 1996, where she observes that for modern moral skepticism "ethics is faulted because it is unable to give us an objective view of the world whether it is science in practice or in principle, or just common-sense, which is deemed to give us such an objective view" (p. 210, emphasis added).

${ }^{9}$ As Hankinson (1994, n. 33) points out, this is not exactly the way the Pyrrhonists would express their view since, as we will see, they do not investigate whether there are objective moral values, but whether anything is good, bad, or indifferent by nature. Nonetheless, for the purpose of this paper this difference is not important.

${ }^{10}$ According to Sextus, by suspending judgment the Pyrrhonist unexpectedly achieves unperturbedness (ataraxia) (see esp. PH I 25-29); but this point is not relevant to my present purposes.

${ }^{11}$ It follows from this that when I translate the term anepikritos as 'unresolvable', I do not use this word in a strong sense. I think that if the arguments advanced by the parties in a dispute have appeared to have equal force, it is consistent to say that at least so far it has not been possible to adhere to any of the contending positions.

${ }^{12}$ Note that even though the person that the Pyrrhonist calls "the dogmatist" is arrogant, and convinced that his doctrines cannot be false, he does not prefer authority to arguments and evidence, but bases his assertions upon reasoned theories.

${ }^{13}$ There are two important points that must be noted. First, the Pyrrhonist is not committed to the criteria of justification formulated in the three Agrippan modes mentioned above, but only uses them because such criteria are accepted by the dogmatists themselves as the basis of their own reasoning. Second, the Pyrrhonist does not rule out the possibility of ever finding an assertion or set of assertions that could meet the dogmatists' conditions for justified belief.

${ }^{14}$ I take here for granted that the Pyrrhonists suspended judgment about the existence of the external world. This is a controversial issue; for discussion, see Burnyeat, 1982, sec. III; Everson, 1991; Fine, 2003.

${ }^{15}$ Annas points out that one of the crucial differences between ancient and modern moral skepticism is precisely the non-local character of the former (see Annas, 1998, pp. 203-204, 207; also Annas, 1996, pp. 209-210).

${ }^{16} \mathrm{I}$ wish to thank an anonymous referee for helpful suggestions.

\section{REFERENCES}

Annas, J. and Barnes, J. (1985). The Modes of Scepticism. Cambridge: Cambridge University Press.

Annas, J. (1996). "Scepticism about Value," in R. H. Popkin (ed.) Scepticism in the History of Philosophy: A Panamerican Dialogue. Archives internationales d'histoire des idées. Dordrecht-Boston-London: Kluwer Academic Publishers, pp. 205-218.

Annas, J. (1998). "Doing Without Objective Values: Ancient and Modern Strategies," in S. Everson (ed.) Companions to Ancient Thought IV: Ethics. Cambridge: Cambridge University Press, pp. 193-220.

Bett, R. (1988). “Is Modern Moral Scepticism Essentially Local?” Analysis 68, pp. 102107. 
Black, R. (1989-1990). "Moral Scepticism and Inductive Scepticism," Proceedings of the Aristotelian Society 90, pp. 65-82.

Burnyeat, M. (1982). "Idealism and Greek Philosophy: What Descartes Saw and Berkeley Missed?" The Philosophical Review 91, pp. 3-40.

Everson, S. (1991). "The Objective Appearance of Pyrrhonism," in S. Everson (ed.) Companion to Ancient Thought II: Psychology. Cambridge: Cambridge University Press, pp. $121-147$.

Fine, G. (2003). "Sextus and External World Scepticism," Oxford Studies in Ancient Philosophy 24, pp. 341-385.

Garner, R. T. (1990). "On the Genuine Queerness of Moral Properties and Facts," Australasian Journal of Philosophy 68, pp. 137-146.

Hankinson, R. J. (1994). "Values, Objectivity and Dialectic; The Sceptical Attack on Ethics: its Methods, Aims, and Success," Phronesis 39, pp. 45-68.

Kleiman, L. (1989). "Morality as the Best Explanation," American Philosophical Quarterly 26, pp. $161-167$.

Mackie, J.-L. (1977). Ethics: Inventing Right and Wrong. Harmondsworth: Penguin.

Schofield, M. and Striker, G. (eds.) (1986). The Norms of Nature: Studies in Hellenistic Ethics. Cambridge: Cambridge University Press.

Snare, F. (1984). "The Empirical Basis of Moral Scepticism," American Philosophical Quarterly 21, pp. 215-225. 